\title{
COMUNICAÇÃO E MANIPULAÇÃO EM ANÚNCIO DE CERVEJA
} COMMUNICATION AND MANIPULATION IN BEER ANNOUNCEMENT

\author{
Arlene Lopes Sant'Anna \\ UNIFAE - Centro Universitário
}

Resumo: Este artigo analisa um anúncio da cerveja Antarctica, fundamentado na semiótica greimasiana. A partir dessa teoria podemos discutir as relações entre linguagens sincréticas, efeitos de sentido, contexto da enunciação e figurativização de temas e valores no discurso. Na configuração discursiva, será possível desvendar qual o tipo de manipulação utilizada pelo enunciador na construção dos anúncios, para levar os jovens brasileiros ao consumo da cerveja.

Palavras-chave: publicidade; consumo; semiótica; manipulação; discurso.

Abstract: This article analyzes an Antarctica beer advertisement based in French semiotics. From the theoretical grounds set by Greimas and his followers, we discuss the relationship among syncretic languages, meaning effects, enunciation context and the social values. In the discursive configuration, we can understand the manipulation strategies used by the enunciator in the construction of the advertisement for the consumption of beer among the brasilian youngs.

Keywords: advertisement; consumption; semiotics; manipulation; speech.

Diariamente, somos "bombardeados" com muitos anúncios publicitários de variadas marcas de cerveja, seja em meios impressos, seja em meios eletrônicos. A concorrência entre as empresas é tal que exige a intervenção de agências de publicidade para instigar o consumo de seus produtos. Em face da situação, as agências se esmeram na criação das campanhas e, principalmente, nas estratégias de persuasão. O objetivo maior é aumentar o consumo e destacar o produto no mercado.

Não podemos negar que os anúncios de cerveja veiculados na televisão se apresentam cada vez mais criativos, tendo em vista que a concorrência entre as marcas exige que se estabeleçam os slogans identificadores da marca, como "a redondinha", "a número 1", "refresca até pensamento", etc. Em se tratando de publicidade, em linhas gerais, a estratégia é a constância dos anúncios com slogans repetitivos e fáceis de memorizar, com o propósito de relacioná-los à marca da cerveja em exposição. Além disso, os anúncios sempre trazem um toque humorístico ou alguma situação inusitada, o que favorece a memorização do enunciatário.

O que interessa a este estudo são os anúncios televisivos, pois este é o meio que tem maior potencial de atingir a população. E é na esteira da semiótica greimasiana que 
queremos saber como são construídas as estratégias de manipulação para favorecer o consumo de cerveja.

\section{O texto sincrético}

Toda produção televisiva é considerada um texto sincrético, já que são filmes ou gravações e, para a semiótica greimasiana, esses discursos mantêm sistemas de relações entre diferentes tipos de linguagem, mas resultando em um todo de sentido. Para melhor esclarecimento, vale lembrar que os conjuntos de significantes de um texto fílmico ou televisivo - trilha sonora, ruídos, enfoque de câmeras, cores, falas, gestos, iluminação - são chamados de semióticas sincréticas, que se manifestam como um sistema de relações entre diferentes linguagens na produção dos efeitos de sentido. Entretanto, para haver esse "todo de sentido", é necessário que esse sistema seja organizado de forma hierárquica. Por outro lado, o enunciador busca produzir efeitos de sentido de realidade ou de verdade, para que o enunciatário acabe se identificando com eles, direta ou indiretamente, e seja levado a crer no enunciado veiculado.

O sincretismo dos textos televisivos publicitários é pensado como parte de uma estratégia de captura e manutenção da atenção do enunciatário. Como sabemos, o texto é constituído de dois planos: o plano do conteúdo, em que o texto diz o que diz, lugar do inteligível e do passional, e o plano da expressão, que não só "carrega" os conceitos como também é o lugar do sensível, dos efeitos de contrastes, movimentos, profundidade, etc. É claro que o plano do conteúdo também instiga nossa sensibilidade, mas a expressão trabalha os sentidos de maneira mais direta, menos mediada pela razão.

O enunciador-publicitário trabalha evidentemente com o propósito de estimular no enunciatário-alvo o consumo de uma idéia ou de um produto. No caso do anúncio em estudo, o enunciador precisa desencadear um pragmatismo do fazer, ou seja, que o enunciatário compre a cerveja e, para isso, enriquece semanticamente o anúncio agregando valores à cerveja, como veremos na descrição do texto. A persuasão do enunciador e a interpretação do enunciatário se encontram no discurso publicitário.

Foram examinados 25 anúncios de cerveja, (Antarctica, Brahma e Skol) veiculados nos anos de 2000, 2001, 2002 e 2003, e se constatou que a grande maioria apresenta textos com estratégias discursivas de manipulação por tentação e por sedução. $\mathrm{O}$ que os anúncios colocam é que os consumidores da cerveja partilham um sistema positivo de valores projetados na imagem de que o produto é irresistível, pois remete a cenários de confraternização, refrescância, descontração e mulheres bonitas. Se o enunciatário tornar-se um consumidor, fará parte do jogo, pois a estratégia da persuasão está baseada na competência atribuída ao enunciatário. O contrato se baseia na crença nesse sistema, e assim o possível consumidor é modalizado pelo querer, desencadeando a performance de comprar a cerveja, objeto-valor apresentado pelo anúncio.

Foi selecionado um anúncio para ilustrar como o enunciador constrói o texto empregando as estratégias de manipulação por sedução e por tentação, com o objetivo de persuadir o enunciatário a consumir a cerveja Antarctica. (2000, p. 47) ensina que um conjunto de temas e figuras materializam uma visão de mundo, ou seja, o discurso pode "parecer verdadeiro", se o destinatário identificar no simulacro suas verdades e suas crenças. O ideal para que haja eficácia na manipulação é que o enunciador e o enunciatário pertençam à mesma formação discursiva, ou seja, tenham a mesma visão de mundo, fato que garantiria a identificação com os valores enunciados.

A manipulação é entendida como um contrato em que o enunciador quer fazercrer e o enunciatário, em seu fazer-interpretativo, pode tanto acreditar e aceitar como não 
acreditar e não aceitar. Nesse jogo de manipulação, no caso do anúncio de cerveja, o enunciador visa a atingir um enunciatário específico, o qual é idealizado como portador dos mesmos valores transmitidos pelo discurso. Ao aceitar o contrato, o enunciatário deixa-se manipular e, conseqüentemente, consome a cerveja.

Na década atual, temos observado que a maioria dos comerciais de cerveja são produzidos para conquistar o público jovem. Para isso, o enunciador prepara as estratégias necessárias à conquista e adesão do enunciatário, ou seja, é mister instalar elementos pertinentes ao universo da juventude, figurativizado por jovens, mulheres bonitas, pessoas saudáveis e ativas, praia, cores vibrantes, sol, calor, irreverência, descontração, confraternização, além do tom hilário de situações inusitadas. Podemos até mesmo afirmar que os anúncios são dirigidos para um público numa faixa etária aproximada de 20 a 25 anos. Para dar início ao exame das estratégias discursivas utilizadas, será usada uma descrição verbal do anúncio, em seguida procede-se à análise.

\section{Descrição}

\section{ORDEM VISUAL}

\section{ORDEM SONORA}

Noivo: Meu sogro vai me matar....

Acompanhante: Ainda vai achar que a culpa

é minha!

Os jovens, aparentando uns 25 anos, estão vestidos com fraques e o do meio traz uma flor na lapela, o que faz supor que seja o noivo. Andam apressados, conversando.

Plano próximo: jovens olham através de uma janela de um bar.

Barulho de tampa de garrafa sendo aberta.

Vêem uma garrafa de Antártica.

Plano-detalhe na cerveja sendo derramada.

Copo de cerveja gelada que transborda.

Plano close: noivo olha a cerveja.

Plano de conjunto: noivo olha para a igreja.

Plano geral: igreja, escadaria da igreja com tapete vermelho, limusine, fotógrafos,convidados chegando...
Sinos tocando 
Plano close: dentro do bar, noivo olha a cerveja no balcão e molha os lábios.

Plano detalhe: os três jovens pegam copos de cerveja

Plano close: noivo bebe a cerveja.

Plano próximo: jovens bebem.

Plano próximo: noivo pega salgadinho em forma de rosquinha, aproxima da boca, retira da boca, olha o salgadinho e faz expressão de desagrado, o que pressupõe a associação da rosquinha à aliança.

Plano detalhe: garrafa de cerveja Antarctica e copo cheio de cerveja gelada.
Risadas, música.

Aaaah!!!!

Garçom: aceita um salgadinho? Noivo: aceito!Hummmmmm.....
Plano médio: noivo chegando apressado com os amigos na igreja. À escadaria da igreja, a noiva com os convidados.
Só se for Antárctica...!!

Noivo: meu amor, me perdoe...

Esquema I: Descrição do comercial.

\section{Análise}

Para o exame e a apreciação do texto, a organização da narrativa é vista como a simulação do fazer que transforma o mundo, posto que as estruturas narrativas simulam tanto a história do homem em busca de valores, ou à procura de sentidos, quanto a dos contratos e dos conflitos que marcam o relacionamento humano. Para entender a organização narrativa, é necessária uma descrição do espetáculo que se apresenta, determinando os participantes e os papéis que desempenham na encenação.

$\mathrm{Na}$ narrativa concretizada pelo anúncio, temos o ator discursivo noivo, que recobre o papel actancial de sujeito do estado: é o noivo e se dirige à igreja para a cerimônia do casamento. Nesse primeiro momento, está em conjunção com os valores casamento, compromisso com a noiva, horário da cerimônia, garantia da sua presença e responsabilidade que se propõe a assumir posteriormente. Ao mencionarmos o noivo, consideramos os amigos que o acompanham como coadjuvantes da ação.

No segundo momento, ao avistar a cerveja pela janela e entrar no bar, o noivo recobre o papel actancial do sujeito do querer-fazer. Assim, o sujeito noivo entra em disjunção com o objeto casamento, para entrar em conjunção com os valores da cerveja. No terceiro momento, o noivo se lembra de seu compromisso, deixa a cerveja e se dirige ao encontro da noiva na igreja. Vale destacar que o noivo se dirige ao encontro da noiva com sinais evidentes de culpa, por ter-se deixado atrasar por causa da cerveja. Os programas narrativos são representados da seguinte forma: 
1. $\mathrm{PN}=\mathrm{F}$ (casar) $\left[\mathrm{S}_{1}\right.$ (noivo e coadjuvantes) $\rightarrow \mathrm{S}_{2}$ (noivo e coadjuvantes) $\cap \mathrm{O}_{\mathrm{v}}$ (casamento)]

$\mathrm{PN}=$ programa narrativo $\mathrm{F}=$ função $\mathrm{S}_{1}=$ sujeito do fazer

$\mathrm{S}_{2}=$ sujeito do estado $\mathrm{O}_{\mathrm{v}}=$ objeto de valor

O sujeito de estado (noivo) está em conjunção com o objeto-valor casamento, representado no discurso pelas figuras do vestuário, da pontualidade ao chegar à igreja, em que se inscrevem os temas responsabilidade, compromisso, maturidade, amor, estabilidade. É a relação transitiva do sujeito noivo com o objeto-valor casamento como representação, na sintaxe, da relação básica homem-mundo.

2. $\mathrm{PN}=\mathrm{F}$ (tomar cerveja) $\left[\mathrm{S}_{1} \cap \mathrm{O}_{\mathrm{v}}\right.$ (cerveja) $\rightarrow \mathrm{S}_{2} \cup \mathrm{O}_{\mathrm{v}}$ (casamento) $]$

O sujeito do estado (noivo) tem seu estado alterado ao entrar no bar e beber a cerveja, ou seja, o sujeito do fazer entra em conjunção com outro objeto-valor, a cerveja, que representa alegria, descontração, irreverência, refrescância e, assim o sujeito de estado entra em disjunção com o objeto-valor casamento. $\mathrm{O}$ mesmo ator discursivo (noivo) recobre dois papéis actanciais: é o sujeito de estado e o sujeito do fazer. A transformação é entrar no bar em vez de seguir o caminho da igreja.

\section{3. $\mathrm{PN}=\mathrm{F}$ (casar) $\left[\mathrm{S}_{1} \cup \mathrm{O}_{\mathrm{v}}(\right.$ cerveja $) \rightarrow \mathrm{S}_{2} \cap \mathrm{O}_{\mathrm{v}}$ (casamento) $]$}

O sujeito do fazer, ao lembrar-se de seu compromisso, sai do bar alterando seu estado, ou seja, o sujeito do fazer entra em disjunção com o objeto-valor cerveja e, conseqüentemente, entra em conjunção com o primeiro objeto-valor, o casamento. Sujeito de estado e sujeito do fazer estão representados pelo ator noivo, como no programa anterior, mas a transformação é dirigir-se à igreja para se casar.

\section{A manipulação}

Ainda que as fases da manipulação e da competência não estejam explícitas, elas estão pressupostas: o noivo deve dirigir-se à igreja e casar-se, no entanto não resiste à visão da cerveja gelada, espumante, e entra no bar, esquecendo seu compromisso. A seguir, ele se livra da manipulação e retoma o primeiro contrato: casar-se. Não podemos ignorar que não é só o plano de expressão que pode manipular o enunciatário do discurso, pois o plano de conteúdo é também uma estratégia, ou seja, a "historinha" do noivo que deixa de comparecer à igreja no dia de seu casamento, considerado pelo senso comum um dia muito importante, pode gerar no enunciatário uma expectativa, um querer saber se a cerveja pode fazê-lo mudar de idéia e abandonar a noiva no altar.

Considerando o percurso do destinador-manipulador, Barros (1997, p. 28) afirma que "o percurso do destinador é examinado não na perspectiva do sujeito de estado que recebe os valores modais, mas do ponto de vista do sujeito doador ou destinador desses valores...". Por um lado, o texto apresenta o destinador-manipulador noiva/casamento e por outro lado, há o destinador-manipulador cerveja/diversão. Os dois destinadores são sujeitos doadores de valores modais, sendo que os valores do casamento são amor, estabilidade, compromisso, responsabilidade, convívio familiar, e os valores da cerveja são refrescância, irreverência, alegria, instabilidade, prazer, efemeridade. Barros (Ibidem) acrescenta: 
As ações do sujeito e do destinador diferenciam-se nitidamente: o sujeito transforma estado, faz-ser e simula a ação do homem sobre as coisas do mundo; o destinador modifica o sujeito, pela alteração de suas determinações semânticas e modais, e faz-fazer, representando, assim, a ação do homem sobre o homem.

No texto em estudo, o noivo apresenta duas performances: a de casar, representada pelo vestuário, a igreja, o diálogo e a de beber a cerveja. Apresentam-se, então, dois destinadores: o destinador casamento e o destinador cerveja.

Destinador-manipulador $\rightarrow$ casamento $=$ valores de viver em família: convívio social, amor, compromisso, responsabilidade.

Antidestinador-manipulador $\rightarrow$ cerveja $=$ valores da bebida alcoólica: refrescância, descontração, alegria, lazer, efemeridade, instabilidade.

Destinatário-manipulado $\rightarrow$ o noivo

\section{Sedução e tentação}

Considerando a manipulação da cerveja, vemos que o destinador-manipulador Antarctica doa ao destinatário-sujeito, noivo, os valores modais do querer-fazer. A cerveja manipula o noivo apresentando uma imagem positiva da sua competência e, nesse processo de "sedução", o noivo acredita que beber uma cerveja em um dia de calor, com um pouco de descontração não fará mal algum. No processo de manipulação por "tentação", ele acredita que pode beber, pois beber a cerveja gelada é o que o sujeito-destinatário aspira. O noivo se deixa persuadir, acredita nos valores doados pelo destinador-manipulador, a cerveja Antarctica, aceita o contrato, passa a querer-fazer e recebe os valores contratuais, ou seja, a refrescância da cerveja em um dia de calor e tensão, a descontração, o momento com amigos e o ambiente alegre proporcionado pela cerveja.

Ao aceitar o contrato do destinador Antarctica, o jovem é sancionado negativamente pelo destinador casamento, com o atraso na chegada à igreja, fato mal visto pela tradição, já que é a noiva que deve chegar atrasada e não o noivo. Dessa maneira, a manipulação da cerveja Antarctica não foi bem sucedida, pois o sujeito-manipulado, então dotado de um não-querer-fazer ou um não-dever-fazer, desiste da cerveja e recebe a sanção positiva de recuperar os valores do casamento, representado pela saída do bar e pela afirmação "Meu amor, me perdoe...". Abaixo temos o quadro da estratégia de manipulação, para melhor compreensão do jogo. ${ }^{1}$

\begin{tabular}{|l|l|l|}
\hline & \multicolumn{1}{|c|}{$\begin{array}{c}\text { Competência do } \\
\text { destinador-manipulador }\end{array}$} & Alteração na competência \\
\hline SEDUÇÃO & $\begin{array}{l}\text { SABER (imagem positiva do } \\
\text { destinatário) }\end{array}$ & QUERER-FAZER \\
\hline TENTAÇÃO & PODER (valores positivos) & QUERER-FAZER \\
\hline
\end{tabular}

Quadro I: Competências.

\footnotetext{
${ }^{1}$ Adaptado de: BARROS, 1997.
} 


\section{A enunciação e os efeitos de realidade}

"Por efeitos de realidade ou de referente entendem-se as ilusões discursivas de que os fatos contados são 'coisas ocorridas', de que seus seres são de 'carne e osso', de que o discurso, enfim, copia o real." Barros (1997, p. 59). O texto televisivo goza dessa prerrogativa, pois o enunciador sabe que, ao copiar o real, fará com que o enunciatário o identifique como tal, seja diretamente, quando se vê na realidade criada, seja indiretamente, quando identifica alguma situação semelhante. Isso concorre para que o enunciatário creia na ocorrência e seja persuadido por seus valores. Segundo Carvalho (1996, p. 106), "para ser eficaz, a mensagem publicitária deve capitalizar a relação que existe entre a organização das sociedades e a questão de identidade".

Nesse anúncio, o discurso instala o noivo e seus coadjuvantes em um dia ensolarado, caminhando apressadamente na rua, com a tensão e o calor aliados à tentadora visão de um copo gelado e espumante de uma cerveja. Essa situação fez com que o propósito anterior de ir à igreja e cumprir o compromisso de casar fosse esquecido para dar lugar ao desejo de beber cerveja. A visão foi tão irresistível que os rapazes entraram no bar e começaram a beber a cerveja em meio à música, às risadas e à descontração. $\mathrm{E} o$ compromisso do casamento só não foi totalmente esquecido em função da cerveja Antarctica por causa do detalhe do salgadinho oferecido pelo garçom, que fez o noivo associar a forma circular do salgadinho às alianças e imediatamente se lembrar do compromisso e sair do bar, mesmo a contragosto, sensação que se pode observar pela expressão facial de desagrado do noivo. A associação do salgadinho com as alianças do casamento trouxe o noivo à realidade, caso contrário, os rapazes ficariam bebendo e não haveria casamento. Podemos dizer que o enunciador ironiza ao colocar em risco o valor social do casamento por causa de uma cerveja. Em outras palavras, no discurso do anúncio da cerveja Antarctica, o que está em jogo é a manipulação por tentação, representada no sistema de valores oferecidos pela cerveja Antarctica, os quais podem colocar em risco qualquer compromisso sério.

Esta análise é exemplar para mostrar a tentação e a sedução como estratégias de manipulação, empregadas comumente nos anúncios de cerveja na televisão. As estratégias são empregadas, na construção das variações discursivas e textuais do discurso básico de consumo de cerveja, por um enunciador que quer persuadir o enunciatário de que não há nada melhor do que uma cerveja gelada e refrescante. As figurativizações e os temas a elas subjacentes, nos enunciados, são constituintes do conjunto da formação discursiva utilizada no texto que materializa sua ideologia. A esse respeito Fiorin (2000, p. 47) explica:

A análise vai mostrar a que formação discursiva pertence determinado discurso. O sujeito inscrito no discurso é um 'efeito de sentido' produzido pelo próprio discurso, isto é, seus temas e figuras é que configuram a 'visão de mundo' do sujeito. Se, do ponto de vista genético, as formações ideológicas são materializadas nas formações discursivas, na análise, é o discurso que vai revelar quem é o sujeito, qual é a sua visão de mundo.

Em todos os anúncios, as figuras - praia, suor, bares, garrafa gelada de cerveja, espuma, copos cheios, jovens, pouca roupa ou roupas leves - revelam os temas subjacentes, conseqüentemente revelam os valores presentes no discurso. Os valores são os estabelecidos pelo senso comum: juventude, saúde, calor, lazer, alegria, descontração, irreverência, confraternização, sensação de sede. 
CASA, Vol.6 n.1, julho de 2008

Em face disso, o enunciador passa a ser o "reprodutor da verdade", o discurso se investe de veridicção, o enunciatário reconhece o contexto apresentado, um ambiente de alegria, de descontração, de saciedade, proporcionado pelo consumo da cerveja. E ela passa a ser o objeto-valo, ou objeto de desejo, que leva o enunciatário-alvo a querer-fazer, ou seja, querer-bebe. E também oferece ao enunciatário ter imagem positiva de si mesmo, pois afinal beber uma cerveja gelada é bem merecido em um dia de calor.

\section{Referências Bibliográficas}

BARROS, D. L. P. de. Teoria semiótica do texto. São Paulo, Ática, 1997.

CARVALHO, N. de. Publicidade a linguagem da sedução. São Paulo: Ática, 1996.

FIORIN, J. L. Linguagem e ideologia. São Paulo: Ática, 2000. 